Proceedings of the Annual Scientific Meeting of the International Medical Society of Paraplegia held at Stoke Mandeville Hospital on 22nd to 24th July 1970-Part III

\title{
REGULATION OF THE CARDIOVASCULAR SYSTEM IN PATIENTS WITH FRESH INJURIES TO THE SPINAL CORD-PRELIMINARY REPORT $^{1}$
}

By F. W. Meinecke, M.D., K. A. Rosenkranz, M.D., and C. M. Kurek From the Spinal Centre of the Surgical Department and the Cardiological Centre of the Medical Department of the Berufsgenossenschaftlichen Krankenanstalten Bergmannsheil, Bochum, Germany

\section{INTRODUCTION}

PREvious studies in the regulation of the cardiovascular system after injuries of the spinal cord were mainly carried out in patients with long-standing paraplegia. Little is known regarding respective findings during the initial injury phase with systematic observations of the course of this condition.

\section{MATERIAL}

For this reason we studied the reaction of the blood pressure and of the pulse rate in a total of $4 \mathrm{I}$ patients with traumatic paraplegia and tetraplegia. Twentyeight of these were admitted to the hospital within the first 24 hours. The other I3 patients were admitted up to 35 days after injury, i.e. during a period when

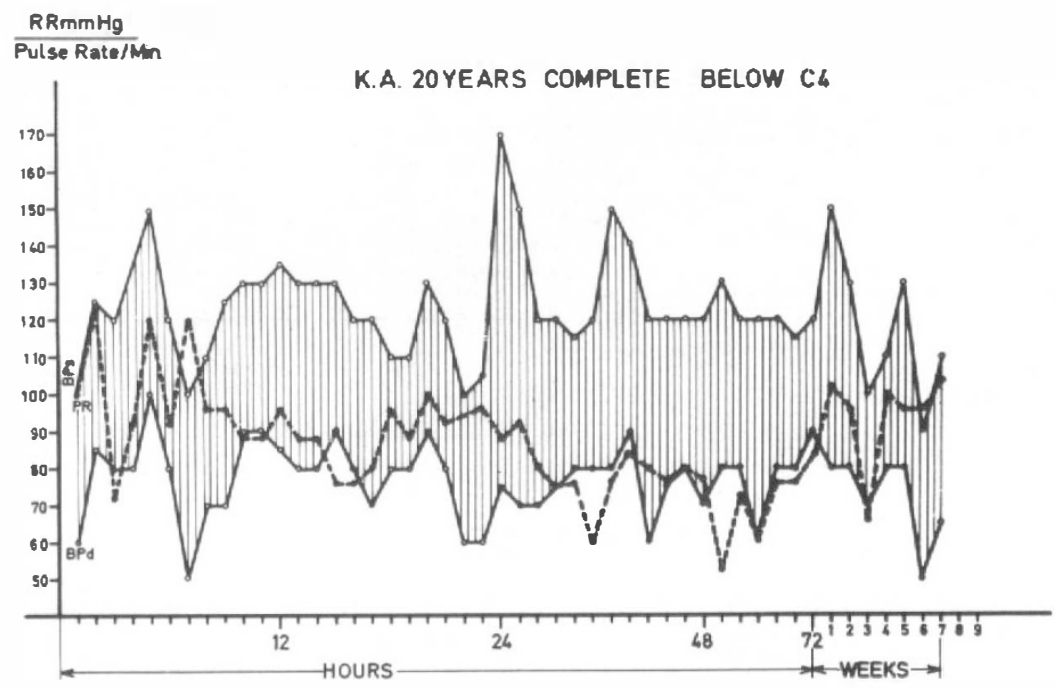

FIG. I

1 These investigations were carried out with financial support of the "Kommission der Europäischen Gemeinschaften" in Luxemburg.

H 
bed rest was still required. During the initial stage of the injury the blood pressure and pulse rate were measured hourly and subsequently at progressively longer intervals. As a supplement to these determinations in the horizontal position the respective controls were carried out eight weeks after injury when the patients were first sitting up in bed at $90^{\circ}$ and subsequently every four weeks when standing was attempted at the tilting table. In these studies the period of observation was always I5 minutes.

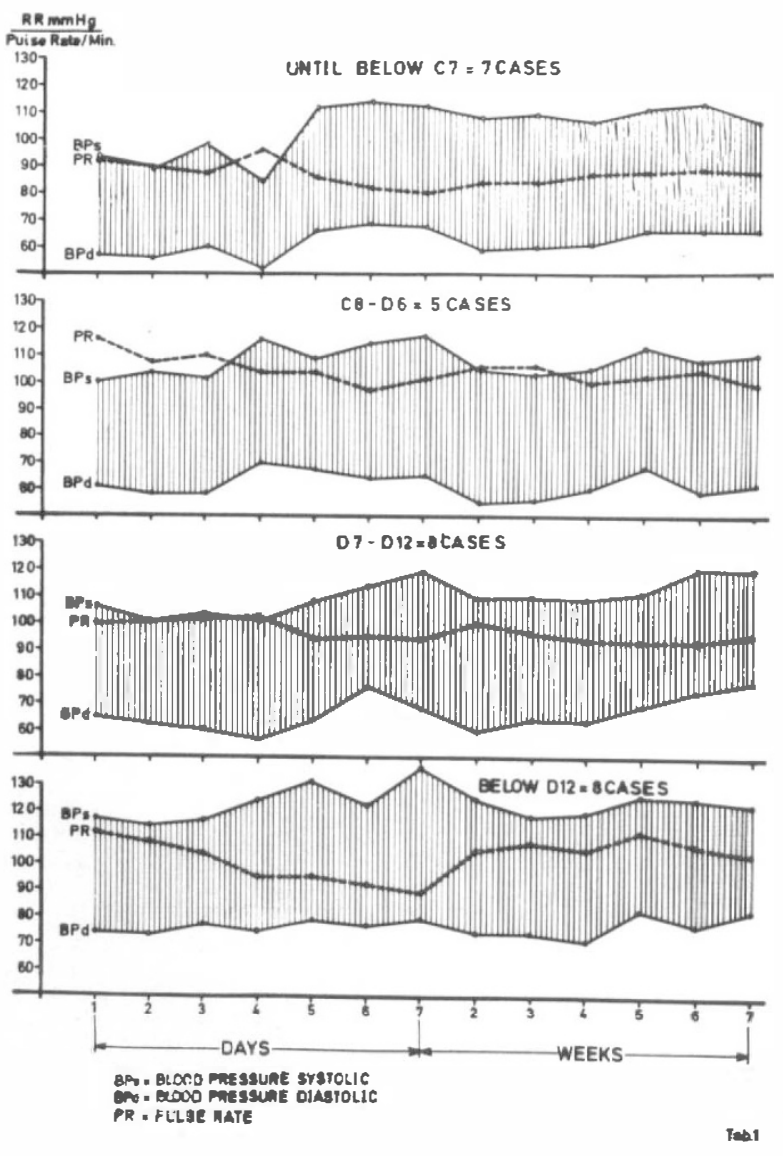

FIG. 2

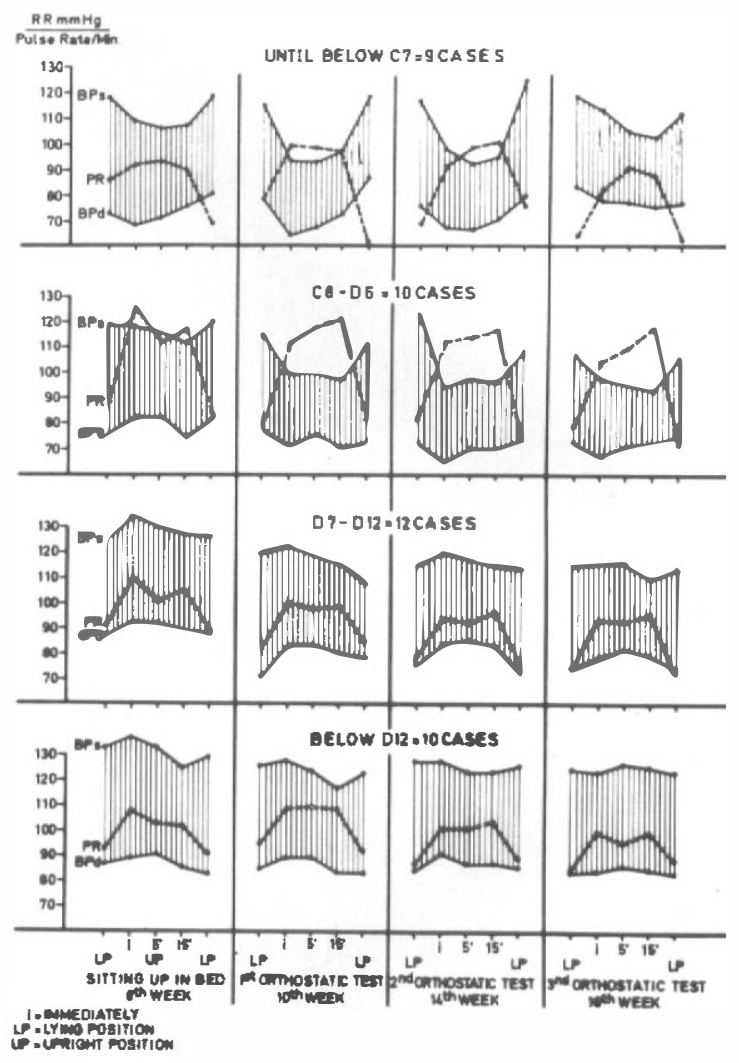

FIG. 3

\section{RESULTS}

The results obtained by this method are presented as a preliminary report for discussion. In this study we have subdivided the patients into four groups according to the location of the lesion: cervical (down to and including $\mathrm{C}_{7}$ ), upper thoracic (C8-D6) lower thoracic (D7-Di2), lumbar (below Dr2).

Figure 2 shows the mean blood pressure and pulse rate of 28 patients with fresh injuries which were measured regularly in the horizontal position. Up to the end of the first week one measured result per day is given and from then on, 
up to the seventh week, one measured result per week. It is noticeable that the systolic and diastolic blood pressures of all four groups are markedly decreased during the first few days. Later a certain amount of stabilisation seems to occur. The group of patients with injuries to the lumbar cord shows normal values from the fourth day onwards. During the initial stage of injury the pulse rate is definitely increased. After several days the mean values show a tendency to fall, but, mainly in patients with injuries to the upper thoracic cord, the pulse rate shows appreciable acceleration on the average until the seventh week.

Continuous measurement of the blood pressure and of the heart rate in the individual case showed considerable fluctuation which impaired the informative value of the mean of the group, particularly during the first few days. As an example we would like to show this in Figure I in a 20-year-old man with an injury below $\mathrm{C}_{4}$. For this patient a total of $4 \mathrm{I}$ values measured during the first three days are given. The severe fluctuations of the blood pressure are especially remarkable.

Figure 3 presents the mean blood pressures and pulse rates of $4 \mathrm{I}$ cases while sitting up in bed and during the first three attempts at standing at the tilting table. This shows that patients with lesions of the lower thoracic and lumbar cord are hardly affected. In contrast to this the groups of patients with injuries to the cervical cord and to the upper thoracic cord show considerable orthostatic reactions. In both groups the fall of the systolic blood pressure is particularly impressive. Furthermore, it is remarkable that patients with injuries of the upper thoracic cord show the most severe increase in pulse rate when standing. In these patients cardiovascular control remains poor during the subsequent course whereas in patients with injuries to the cervical cord adaptation mechanisms obviously become effective later on.

\section{DISCUSSION}

From this preliminary report one can conclude that cardiovascular control is unfavourably affected in patients with traumatic damage to the spinal cord. In this respect the extent of limitation is obviously related to the level of the lesion. In patients with lesions of the lower thoracic and lumbar cord the effects of cardiovascular control are already relatively minimal during the initial stage of injury. During the subsequent course extensive stabilisation of the blood pressure and pulse rate occurs and so later on there are no significant alterations in cardiovascular control as compared to healthy persons. However, in this, one must take into consideration the superior training potential of patients with such injuries.

In contrast to this the higher lesions produce severe disorders of cardiovascular control, and injuries of the upper thoracic cord obviously produce stronger effects than those of the cervical cord. In such patients significant improvement was not seen during the whole course of observation of the condition.

In patients with cervical cord lesions it is obviously possible that adaptation mechanisms of peripheral cardiovascular regulation become effective later on. It is a matter for discussion whether this reaction, which was primarily not expected, is related to peculiarities of the course of the sympathetic system. However, it is also possible that a more pronounced increase of the pulse rate fails to materialise in patients with injuries to the cervical cord from a lack of positive chronotropic stimuli from the cervical ganglia. So such patients, compared with patients with 
lesions of the upper thoracic cord, only apparently have somewhat more favourable conditions of cardiovascular control.

\section{CONCLUSION}

If our preliminary results are compared with the observations of Guttmann (1968, I969), Guttmann et al. (I963), Imhof et al. (1962), Maury (I962) and Paeslack (I965), which are made after the 'spinal shock' had subsided, extensive agreement is found. In our studies the critical level also appears to be above D6.

Adaptation potential of patients with lesions to the upper thoracic cord after getting out of bed during the early stage is also surprising, as it is worse than in patients with lesions of the cervical cord. However, in this, one must also take into consideration that associated injuries of the chest occur more frequently in our patients with lesions of the thoracic cord than in patients with lesions to the cervical cord. It is not possible here to consider these associated injuries. Similarly, all groups consisted of patients with incomplete and complete paralysis:

Cervical cord: 9 cases, 6 complete, 3 incomplete.

Upper thoracic cord: Io cases, 8 complete, 2 incomplete.

Lower thoracic cord: 12 cases, Io complete, 2 incomplete.

Lumbar cord: Io cases, 5 complete, 5 incomplete.

The last attempt at standing was undertaken during the eighteenth week, i.e. ten weeks after sitting up at $90^{\circ}$ in bed for the first time. Naturally, the effect of training on the adaptation processes of the cardiovascular system described by all authors has only been present for a short period of time. Further, it remains for more prolonged observations on the course of this condition in the future to clarify this problem. We shall refer to this in later reports. Certainly the loss of tone in the splanchnic and lower leg vessels is even more pronounced during the early stage than later.

\section{RÉSUMÉ}

Tous les auteurs semblent d'accord en ce qui concerne la phase après le choc spinal. Dans nos études, le niveau critique paraît aussi être au-dessus de D6. L'auteur met en cause le manque de tonus au niveau du splanchnique et de la vascularisation des membres inférieurs qui est plus prononcé pendant la phase de début qu'après.

\section{ZUSAMMENFASSUNG}

Die Autoren bestätigen die Beobachtungen früherer Autoren hinsichtlich der kardiovaskulären Veränderungen nach Beendigung des spinalen Schocks bei Querschnittsgelähmten. Ihre eigenen Puls-und Blutdruckuntersuchungen im Initialstadium von Querschnittsgelähmten ergaben sch werere Veränderungen der kardio-vaskulären Kontrolle in oberen Thorakallähmungen verglichen mit Halsmarkverletzungen.

\section{REFERENCES}

Guttmann, L. (1968). The re-orientation of posture and locomotion in the spinal man. Proc. Roy. Soc. Med., 61, 47.

Guttmann, L. (1969). Handbook of Clinical Neurology, Vol. 2. Ed. P. J. Vinken and G. W. Bruyn. Amsterdam: North-Holland Publishing Company.

Guttmann, L., Munro, A. F., Robinson, R. \& Walsh, J. (I963). Effect of tilting on the cardiovascular responses and plasma catecholamine levels in spinal man. Paraplegia, I, 4 . 
IMHOF, P., HEDINGER, F. \& KASER, H. (I962). Über Kreislaufstörungen und Veränderungen 3-Methoxy-4-Hydroxymandelsäure-Ausscheidung im Urin nach traumatischen Läsionen des Rückenmarks. Helv. Med. Act., 29.

MAURY, M. (I962). Des manifestations neuro-végétatives dans les lésions médullaires. Presse méd., 74, I673.

PaEslack, V. (1965). Internistische Störungen beim Paraplegiker. Stuttgart: G. Thieme.

\title{
CARDIOVASCULAR REFLEXES IN TETRAPLEGIA
}

\author{
By J. L. Corbett, H. L. Frankel and P. J. Harris \\ National Spinal Injuries Centre, Stoke Mandeville Hospital
}

\section{INTRODUCTION}

PREvious reports have concluded that cardiovascular control mechanisms in tetraplegics are defective due to disruption of the spinal pathways linking supra-spinal control centres with the peripheral sympathetic outflow (e.g. Bors \& French, I952; Kurnick, I956; Guttmann, Munro, Robinson \& Walsh, I963). There have been few investigations of how this influences the stability of the cardiovascular system in tetraplegics in their day-to-day life or of what control mechanisms exist to permit the degree of rehabilitation which is possible. This is partly because the effects of the various stimuli, which may affect cardiovascular stability and which the tetraplegic may encounter, have not been specifically investigated. There are also confusing and conflicting results in previously published reports due to poor experimental design. Patients with incomplete cord transections have not been differentiated from patients with complete transections; patients with acute cord transections have not been differentiated from those with chronic transections; patients with lesions at various levels have been grouped together and in several instances not enough information has been provided to enable the reader to determine precisely the status of the nervous systems of the patients who have been investigated.

The experiments described in this paper were designed to investigate cardiovascular instability, particularly alterations in blood pressure which occurred in seven tetraplegic patients in response to some stimuli which they normally encountered in their day-to-day life and which might be expected to have a hypertensive or hypotensive effect. The first, bladder percussion, is used to stimulate bladder emptying in tetraplegic patients who are not catheterised and who have automatic bladders (Head \& Riddoch, 1917). The second, skeletal muscle spasms, commonly occur since they are the result of transection of spinal somatic pathways (Head \& Riddoch, 1917; Riddoch \& Head, 1917). Thirdly, tolerance of the upright posture is necessary for rehabilitation to wheel-chair life. Further results and responses to other stimuli are reported elsewhere (Corbett, Frankel \& Harris, I971, $a, b$, and $c$ ).

\section{METHODS}

The observations were made on seven subjects, each of whom had a clinically complete chronic cervical cord transection at a level between $\mathrm{C}_{5}$ and $\mathrm{C}_{7}$. Six of the subjects normally spent their day out of bed in a wheel-chair and at the 